\title{
Substituição de Gordura Animal por Queijo Prato na Produção de Linguiça Suína Tipo Toscana
}

\author{
Guilherme S. Miranda \& Cassandra M. T. Ribeiro
}

Com o propósito de fornecer um produto cárneo diferencial, o objetivo desse trabalho foi a substituição de gordura animal por queijo prato na produção de linguiça tipo toscana. Análises microbiológicas e físico-química foram realizadas e todas estavam dentro do padrão estabelecido. As análises foram realizadas em dois tempos, (zero e trinta dias), as amostras foram mantidas congeladas a $-12^{\circ} \mathrm{C}$. A análises de textura e sensorial tiveram resultados satisfatórios. Os resultados encontrados neste trabalho justificam a produção de um embutido frescal cárneo, com a utilização do queijo prato no lugar da gordura animal, obtendo-se, assim, uma característica diferenciada no produto.

Palavras Chaves: Produto cárneo; legislação; redução de lipídeos; análise sensorial.

In order to offer a meat product differential, the objective was to replace animal fat for cheese platter in the production of sausage Tuscan type. Microbiological analysis and physical chemistry were performed and all were within the established pattern. The analyzes were carried out in two times (zero and thirty days), the samples were kept frozen at $-12^{\circ} \mathrm{C}$. The sensory analysis of texture and had satisfactory results. The findings of this study justify the production of a built frescal meat, cheese using the plate instead of animal fat obtaining a distinctive feature in product.

Keywords: Meat product; legislation; lipid-lowering; sensory analysis. 


\section{Introdução}

A carne suína é a mais industrializada, comercializada e consumida no mundo, consolidando-se nas últimas décadas como fonte de proteína animal de grande importância para alimentação humana. A suinocultura brasileira tem sua maior representação nas regiões Sul (15,6 milhões de cabeças), Sudeste (5,6 milhões de cabeça) e Nordeste (5,2 milhões de cabeças), uma vez que estas regiões representam respectivamente $49,9 \%, 18 \%$ e 16,8\% do rebanho brasileiro (CENTEC, 2004). A partir da Idade Média, uma grande variedade de linguiça passou a ser comercializada, variedades estas fortemente influenciadas pelo tipo de clima predominante na região. Climas frios intensificam as variedades frescais cruas ou defumadas, enquanto que os climas mais quentes encontrados na Itália, parte sul da França e da Espanha levaram a enfatizar os embutidos desidratados, mais precisamente os diferentes tipos de salames (TERRA, 2004).

A linguiça toscana trata-se de um produto cárneo embutido cru e curado, feito a partir da carne suína exclusivamente com adição de tecidos adiposos e ingredientes, acondicionados em envoltórios naturais (tripas) ou artificiais, depois do processo tecnológico e conservação adequada (BRASIL, 1952). Possui características organolépticas próprias como cor, sabor, textura e odor, dependo dos ingredientes incluídos em sua composição. As linguiças constituem os derivados cárneos com maior quantidade fabricada em nosso país (250.000 toneladas em 1994), isso se deve por não exigir alta tecnologia para sua fabricação (TERRA, 2000). Por esse aspecto, deve-se atender aos requisitos mínimos de higiene na obtenção da matéria-prima, manipulação, fabricação e acondicionamento, uma vez que a linguiça toscana não sofre tratamento térmico que ajude na redução da flora microbiana inicial e da sua umidade que é de no máximo 70\% (BRASIL, 2000).

O queijo é um dos mais antigos alimentos preparados que a história da humanidade registra. A arte da fabricação de queijos teve seu início perdido num passado, milhares de anos antes do nascimento de Cristo. Os egípcios estão entre os primeiros povos que cuidaram do gado e tiveram, no leite e no queijo, fonte importante de sua alimentação (ALBUQUERQUE, 2002).O queijo é a coalhada que se forma com a coagulação do leite de alguns mamíferos pela adição de coalho ou enzimas coagulantes e/ ou pelo ácido láctico, produzido pela atividade de determinados micro-organismos presentes normalmente no leite ou adicionados a ele intencionalmente; dessora-se a coalhada por corte, aquecimento ou prensagem, dando-lhe forma em moldes e, em seguida, submetendo-a à maturação durante determinado tempo a temperaturas e umidades relativas definidas (ORDOÑEZ, 2005). O queijo prato encontra-se entre os mais consumidos no Brasil. É classificado como um queijo gordo, de média umidade e de massa semicozida, obtido por coagulação enzimática do leite, complementada pela ação de bactérias láticas específicas (EMBRAPA, 2005).

O Produto deve apresentar consistência elástica, textura macia e compacta, podendo apresentar pequenas olhaduras bem distribuídas.

\section{Materiais e Métodos}

A pesquisa experimental foi realizada na Faculdade de tecnologia Senai Toledo/PR, no período de maio a setembro de 2015. Elaborou-se uma formulação de linguiça tipo Toscana que teve como base a carne suína $(65,0 \%)$, queijo prato $(18,5 \%)$, água gelada $(8,5 \%)$, sal $(1,7 \%)$, sal de cura (nitrito e nitrato $1,5 \%)$ e fosfato $(1,5$ $\%$ ), alho $(0,9 \%)$, eritorbato de sódio $(0,8 \%)$, tripolifosfato de sódio $(0,8 \%)$, glutamato monossódico $(0,8 \%)$.

A linguiça foi preparada moendo a carne em disco de $8 \mathrm{~mm}$, os cubos de queijo foram picados manualmente com tamanhos variando entre 0,3 a 0,6 $\mathrm{cm}$, os ingredientes foram pesados, e a seguir foram adicionados, primeiramente, o fosfato com a água para auxiliar na extração das proteínas miofibrilares da carne, e posteriormente adicionado o sal de cura, alho, eritorbato de sódio, tripolifosfato de sódio, glutamato monossódico e por último o queijo prato. Depois da homogeneização, foi deixada a massa curar por 24 horas em temperatura de $2{ }^{\circ} \mathrm{C}$, e em seguida, no processo de embutimento, ou seja, envase da carne em envoltório artificial de celulose, com gomos entre 8 a $12 \mathrm{~cm}$ com calibre 32 seguindo os aspectos higiênico-sanitário adequado e armazenado em temperatura de $-12^{\circ} \mathrm{C}$ em congelador por 30 dias.

Após o desenvolvimento dos produtos, os teores de umidade e cinzas foram determinados gravimetricamente no tempo zero e após 30 dias em duplicata, conforme métodos analíticos do Instituto Adolfo Lutz (IAL, 2008). $\mathrm{O}$ teor de proteínas foi determinado conforme metodologia 
da Associaction of Official Analitycal Chemists (AOAC, 1998) através da técnica de Kjeldahl para análise de nitrogênio total (utilizando o fator de correção de 6,25). Os resultados foram expressos em g $100 \mathrm{~g}-1$ em base seca.

Para extração dos lipídios totais foi empregado o método de extração de gordura a quente, Gold 'Fish segundo Silva (1990). O pH da amostra foi determinado conforme descrito nas instruções do medidor de $\mathrm{pH}$ portátil (Modelo: mPA.210P, Marca: MARKE MBI10P), as análises foram realizadas no tempo zero e após 30 dias da fabricação em duplicata.

As análises microbiológicas de Salmonela $s p$, Coliformes termotolerantes, Clostridium sulfito redutor e Staphylococus aureus foram feitas por laboratório credenciado pelo MAPA. Todas as análises (físicoquímicas e microbiológicas) foram realizadas em duplicata, as análises foram realizadas no tempo zero e após trinta dias da fabricação.

A atividade de água foi realizada conforme descrita nas instruções do medidor de atividade de água (Modelo: S40001901, Marca Decagon, USA) em triplicata.

A análise de textura foi realizada no texturômetro, marca TA. HD. Plus texture analiser. As análises foram realizadas em triplicata, na amostra in natura e assada em forno elétrico, expressas como média e desvio padrão em Newton.

A análise sensorial, aprovada pelo comitê de ética e pesquisa com seres humanos sob número 092677/2015 do produto, foi realizada por meio do teste de aceitabilidade em escala hedônica de 9 pontos no laboratório de processo, com a participação de 63 julgadores não treinados ao consumo de linguiça frescal. Antes de cada teste, os julgadores receberam orientação do método e procedimento da avaliação. Em todos os testes, foram oferecidas água, à temperatura ambiente e linguiça tipo toscana com queijo prato para todos os julgadores. Para o teste, a amostra foi assada na churrasqueira, e servida em pratos descartáveis brancos. A análise sensorial foi aplicada com uma escala hedônica de 9 pontos, em que que para 1 era de desgostei muitíssimo e 9 gostei muitíssimo.

\section{Resultados e Discussões}

\section{ANÁLISES FÍSICO-QUÍMICAS}

Os valores referentes ao resultado da análise de composição centesimal, esta apresentado na Tabela 1 .
Tabela 1. Análises físico-química de linguiça frescal com queijo prato.

\begin{tabular}{|c|c|c|c|}
\hline ANÁLISES & $\begin{array}{c}\text { RTIQ - MAPA } \\
\text { (BRASIL 2000) }\end{array}$ & $\begin{array}{c}\text { AMOSTRA - } \\
\text { TEMPO ZERO }\end{array}$ & $\begin{array}{c}\text { AMOSTRA - } \\
\text { TRINTA DIAS }\end{array}$ \\
\hline Umidade & $70 \%($ MAX) & $70,45 \% \pm 0,75$ & $68,53 \% \pm 2,52$ \\
\hline Cinzas & $*$ & $3,36 \% \pm 0,03$ & $3,02 \% \pm 0,16$ \\
\hline Proteína & $12 \%(\mathrm{MIN})$ & $17,46 \% \pm 0,16$ & $16,65 \% \pm 0,36$ \\
\hline Lipídio & $30 \%(\mathrm{MAX})$ & $4,53 \% \pm 0,30$ & $5,48 \% \pm 0,13$ \\
\hline $\mathrm{pH}$ & $*$ & $5,34 \pm 0,05$ & $5,53 \pm 0,01$ \\
\hline $\begin{array}{c}\text { Atividade de } \\
\text { água }\end{array}$ & $*$ & - & $0,94 \pm 0,0027$ \\
\hline
\end{tabular}

Rtiq - regulamento técnico de identidade e qualidade de linguiças de 31 de março de 2000; Mapa - Ministério da Agricultua, Pecuária e Abastecimento

*não estabelecido, - não realizado.

$\mathrm{Na}$ análise de umidade, encontrou-se para a amostra tempo zero, um maior percentual de umidade, e já na amostra de trinta dias, encontrou-se um menor percentual de umidade ficando dentro dos padrões estabelecidos pelo RTIQ. A amostra de umidade tempo zero encontrou-se $0,64 \%$ fora de padrão estabelecido pelo RTIQ, e a amostra de 30 dias já estava dentro de padrão. Perdas de umidade podem ocorrer na estocagem de produtos cárneos, devido à diminuição da força iônica dos sistemas proteicos, que, com o decorrer do tempo de armazenamento, diminuem a capacidade de ligação com a água, liberando-a. CLAUS (1990). Nascimento (2012), ao estudar linguiças frescais elaboradas com carnes de avestruz e suas características físico-química, encontrou níveis de umidade em torno de $66,8 \%$ sendo utilizadas em sua formulação $75 \%$ de carne de avestruz e $25 \%$ de carne suína.

Os teores de cinzas para a linguiça toscana para os dois momentos, estão apresentados na Tabela 1, não apresentaram diferença entre os tempos.

Para a análise de proteína, a amostra analisada no tempo de trinta dias obteve uma menor porcentagem de proteína, isso ocorre pela maior presença de umidade no produto, ficando em conformidade com o descrito por (CONCEIÇÃO, GONÇALVES, 2009), quanto maior o teor de umidade, menos nutrientes são encontrados. A amostra de trinta dias apresentou uma menor concentração proteica, mas estando dentro do padrão mínimo estabelecido pela legislação RDC 12 de $12 \%$ 
de proteína, porém a legislação não permite a adição de proteína não cárnea para a linguiça tipo toscana. Um teor de $17,65 \%$ de proteína foi relatado por (PAULINO, 2005), esse valor se aproxima do encontrado neste trabalho. Apesar deste valor estar dentro dos padrões estabelecidos no Regulamento Técnico (MAPA, 2000), considera-se desejável que o nível proteico do alimento seja alto.

A análise de lipídio encontrou uma porcentagem de média 5,01 já que para a fabricação da linguiça não se utilizou nenhum tipo de gordura ou toucinho, apenas utilizou-se a gordura da carne suína naturalmente presente e o queijo prato que possui um teor de $15 \%$ de lipídios na porção de trinta gramas, especificados em sua embalagem. Os produtos com maior porcentagem de lipídios geralmente apresentam uma maior maciez e suculência ao consumo. O baixo teor de lipídios está ligado ao fato de que não foi adicionada gordura animal ou vegetal aos produtos, apenas utilizada a gordura da carne suína e do queijo prato em sua fabricação. Alguns julgadores da análise sensorial comentaram sobre a linguiça toscana estar seca, isso ocorre pela quantidade baixa de lipídios, atributos importantes da qualidade da carne, correlacionados com maciez, sabor e suculência no produto final. (PAULINO, 2005) encontrou um teor de lipídio na sua formulação controle de $28,43 \%$ em que foram adicionados $14 \%$ de toucinho para a fabricação, em outra formulação, na qual ele reduz $50 \%$ de toucinho obteve-se um percentual de lipídio de 17,15 alterando significativamente o percentual de lipídios. Estes valores de gordura são maiores aos encontrados neste estudo. Isso pode ser explicado pelo fato das substituições no trabalho destes autores terem ocorrido em percentuais bem maiores aos realizados neste. Com o baixo percentual de lipídios, observa-se uma maior força de cisalhamento, que o contribui para um produto com menor maciez, relatado por julgadores na análise sensorial.

$\mathrm{Na}$ análise do $\mathrm{pH}$, observou-se um elevação após os trinta dias que passou de 5,34 para 5,53 obtendo uma média de 5,44. Este aumento não influenciou na presença de micro-organismos psicrotróficos ou crescimento de flora bacteriana mesófica o que é indesejável para o produto, isso pode ser visualizado na tabela 2 , em que para os micro-organismos clostridium sulfito redutor, coliformes termotolerantes, Staphylococcus aureus e Salmonela sp todos ficaram abaixo do limite permitido pelo regulamento técnico sobre padrões microbiológicos para alimentos de 2 de janeiro de 2001 (RDC 12). No trabalho de Paulino (2005), o qual estudava o efeito da redução de gordura e substituição parcial de sal em linguiça tipo toscana, em sua formulação controle, encontrou uma média de $\mathrm{pH}$ em 5,99 que perto da neutralidade pode ter favorecido o crescimento de micro-organismos, que este $\mathrm{pH}$ pode ter ocorrido por ter uma redução de sal em 50\%, já em uma de suas formulações encontrou-se um $\mathrm{pH}$ de 5,51 que provavelmente houve um declínio no $\mathrm{pH}$ por uma produção de ácido láctico suficiente para impedir o crescimento de uma flora bacteriana.

Tabela 2. Análise de tensão de cisalhamento da linguiça toscana.

\begin{tabular}{|c|c|}
\hline AMOSTRA & $\begin{array}{c}\text { MÉDIA E DESVIO } \\
\text { PADRÃO }\end{array}$ \\
\hline Linguiça in natura & $6,66 \pm 1,02 \mathrm{~N}$ \\
\hline Linguiça assada & $19,36 \pm 0,86 \mathrm{~N}$ \\
\hline
\end{tabular}

A atividade de água encontrada em 0,94 , considerada quantidade alta de água livre, estaria disponível para reações químicas, enzimáticas e microbiológicas que poderiam estar comprometendo as características sensoriais e microbiologias do produto. (VAZ, 2005) relata valores de atividade de água em 0,98 que a maior presença de água livre é propícia ao crescimento de micro-organismo, elemento de suma importância para indústrias de alimentos para garantir a qualidade e segurança alimentar para o consumidor, não colocando em risco de contaminação por micro-organismos patógenos.

\section{ANÁLISE DE TEXTURA}

A força de cisalhamento é uma técnica utilizada para avaliar a maciez de carne. Maior o valor de cisalhamento corresponde à maior forca para romper a amostra. Foi visualizar na Tabela 2 menor força de cisalhamento para a linguiça in natura, isso é determinado por ter maior concentração de umidade. Já para a linguiça assada, a força de cisalhamento foi mais alta, isso pode ser explicado pelo fato de ausência de toucinho em sua formulação. 


\section{ANÁLISES MICROBIOLÓGICAS}

$\mathrm{Na}$ Tabela 3, estão apresentados os dados referentes às análises microbiológicas, realizadas nas linguiças tipo toscana com queijos prato, os resultados estão de acordo com a RDC 12 de 2001, que fala sobre os paramentos microbiológicos de alimentos.

Tabela 3. Análises microbiológicas

\begin{tabular}{|c|c|c|c|}
\hline & RDC 12 & $\begin{array}{c}\text { AMOSTRA - } \\
\text { TEMPO ZERO }\end{array}$ & $\begin{array}{c}\text { AMOSTRA - } \\
\text { TRINTA DIAS }\end{array}$ \\
\hline $\begin{array}{c}\text { C. sulfito } \\
\text { redutor } \\
46^{\circ} \mathrm{C} / \mathrm{g}\end{array}$ & $3 \times 10^{3} \mathrm{UFC} / \mathrm{g}$ & $<1,0 \times 10^{1} \mathrm{UFC} / \mathrm{g}$ & $*$ \\
\hline $\begin{array}{c}\text { Coliformes } \\
\mathrm{a} 45^{\circ} \mathrm{C} / \mathrm{g}\end{array}$ & $5 \times 10^{3} \mathrm{UFC} / \mathrm{g}$ & $<1,0 \times 10^{1} \mathrm{UFC} / \mathrm{g}$ & $<1,0 \times 10^{1} \mathrm{UFC} / \mathrm{g}$ \\
\hline $\begin{array}{c}\text { Estaf.coag. } \\
\text { positiva/g }\end{array}$ & $5 \times 10^{3} \mathrm{UFC} / \mathrm{g}$ & $<1,0 \times 10^{1} \mathrm{UFC} / \mathrm{g}$ & $<1,0 \times 10^{1} \mathrm{UFC} / \mathrm{g}$ \\
\hline $\begin{array}{c}\text { Salmonella } \\
\text { sp }\end{array}$ & $\mathrm{AUSÊNTE}$ & $\mathrm{AUSÊNTE}$ & $*$ \\
\hline
\end{tabular}

Rdc 12 - Regulamento técnico sobre padrões microbiológicos para alimentos de 02 de janeiro de 2001. * não realizado, fonte: elaborado pelo autor (2015)

Todas as amostras apresentaram resultados dentro do padrão estabelecido pela legislação brasileira (RDC $\mathrm{n}^{\mathrm{o}} 12$ de 02 de janeiro de 2001) que estabelece o Regulamento Técnico dos Padrões Microbiológicos para carnes e produtos cárneos. Os sais de cura, utilizados em embutidos, são a base de nitratos e nitritos que geram substâncias inibidoras de micro-organismos especialmente contra Clostridium botulinum, (VAZ, 2005). Já que a linguiça tipo toscana é um alimento comercializado cru, são essenciais as condições sanitárias de boas práticas de fabricação para que o alimento seja seguro, obedecendo aos padrões microbiológicos determinados, não ocorrendo nenhum risco à saúde.

$\mathrm{O}$ grupo coliforme constitui o indicador de contaminação fecal mais frequentemente utilizado, sendo empregado há mais de cem anos como parâmetro bacteriano, na definição de padrões para a caracterização e avaliação da qualidade de águas e alimentos. (SOUZA, 2006).

Dentre os micro-organismos envolvidos em intoxicações alimentares e na produção de metabólitos, capazes de causar moléstias ao homem, as bactérias do gênero Staphylococus coagulase positiva têm se destacado (GENIGEORGIS, 1989). A presença de Staphylococus em alimentos pode sugerir, inadequadas e deficientes condições de manipulação, de limpeza e desinfecção, visto que são indicadores destas. Sua incidência em produtos crus é reduzida devido à competição entre os micro-organismos presentes, um pequeno número destes micro-organismos é previsto em todos os produtos alimentares em que houve manipulação humana (HUSS, 1997).

\section{ANÁLISE SENSORIAL}

A análise sensorial das amostras de linguiças tipo toscana com queijo prato foi realizada após a obtenção dos resultados da análise microbiológica e verificação de que todas as formulações estavam dentro dos padrões estabelecidos. O resultado da análise sensorial do teste de aceitação foi realizado em escala hedônica de nove pontos, classificando quanto o julgador gostou ou desgostou do produto, os resultados estão expressos abaixo na figura 1 .

A Figura 1 mostra que a maioria dos julgadores aprova a linguiça tipo toscana com queijo prato, obtendose uma média de aceitabilidade igual a 8,0 que indica ma grande aceitabilidade pelo público consumidor.

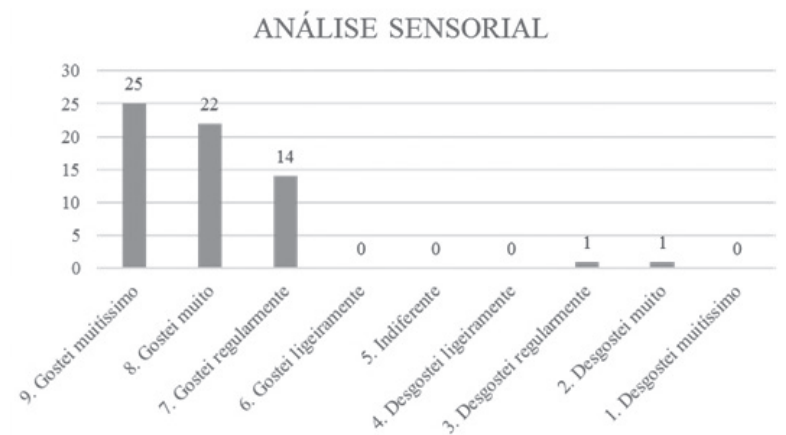

Figura 1. Análise sensorial da linguiça tipo toscana com queijo prato.

\section{Conclusão}

A linguiça tipo toscana com substituição do toucinho no queijo prato apresentou-se dentro dos limites físicoquímicos previstos pela legislação. A substituição do toucinho pelo o queijo prato obtive um nível baixo 
de lipídios, proporcionando característica diferente ao produto. Os padrões físico-químicos foram todos alcançados pela legislação.

Quanto à qualidade microbiológica da linguiça frescal ,pode-se concluir que essa se encontra dentro dos padrões exigidos pela legislação, pois não se constatou presença de clostridium sulfito redutor, coliformes, Stphylococus e Salmonela em nenhuma das amostras analisadas nos dois períodos.

$\mathrm{Na}$ análise sensorial, observou-se boa aceitabilidade pelos julgadores, com média 8,0. Assim, se produzido em grande escala, seria um produto com uma característica diferenciada com uma boa aceitação pelo público consumidor.

\section{Referências}

1. Albuquerque. L. C. - Queijos no mundo - origem e tecnologia. Vol. II. São Paulo: Epamig 2002.

2. AOAC-Association of Official Analytical Chemists. Horwitz, w. (ed). Official methods of analysis of the association of official analytical chemists. 17. Ed. Arlington: aoac inc, 2000. V. 1.

3. Centec, suinocultura - Instituto Centro de Ensino tecnológico. Edições Demócrito Rocha, Ministério da Ciência e Tecnologia, Fortaleza, 2004

4. Claus, J.R.. et al. - low fat, high added water bologna effects ofmassing, pre-blending, and time of addition of water and fat on physical and sensory characteristics. Journal of food science, v.55, n.2, p.338-345, 1990.

5. Empresa Brasileira de Pesquisa Agropecuária - EMBRAPA. Queijo prato. Disponível em $<$ https://www.embrapa.br/busca-depublicacoes/-/publicacao/994402/queijo-prato> acesso em: 10 de março de 2015.

6. GENIGEORGIS, C. - present state of knowledge on staphylococcal intoxication. International journal of food microbiology, v. 9, n. 4, p. 327-360, 1989.

7. HUSS, H. H. - Garantia da qualidade dos produtos da pesca. Departamento de investigação dos produtos da pesca, ministério da agricultura e pesca, fao, documento técnico sobre as pescas, 334, roma, 1997.

8. INSTITUTO ADOLFO LUTZ. Normas analíticas do instituto adolfo lutz. V. 1: métodos químicos e físicos para análise de alimentos, 3. Ed. São paulo: imesp, 2008. P. 13.

9. Ministério da agricultura, pecuária e abastecimento a. Secretária da defesa agropecuária. Departamento de inspeção de produtos de origem animal. Regulamento da inspeção industrial e sanitária de produtos de origem animal. Aprovada pelo decreto $\mathrm{n}^{\circ} 30.691 \mathrm{de}$ 29/03/1952, alterada pelos decretos $n^{\circ} 1255$ 25/06/1962, n 1236 02/09/1994, nº1812 08/02/1996, n²244 04/06/1997. Brasília, 241p. 1997. Disponível em: www.agricultura.gov.br . Acessado em: 09 de março de 2015.

10. Ministério da agricultura, pecuária e abastecimento b. Instrução normativa $\mathrm{n}^{\circ} 4$ de 31 de março de 2000. Regulamento técnico de identidade e qualidade de linguiça. Disponível em: www. agricultura.gov.br . Acessado em: 09 de março de 2015.

11. Ordoñez. A. J. - tecnologia de alimentos: alimentos de origem animal. Vol. 2. Porto alegre: artmed, 2005.

12. PAULINO, Flávia de Oliveira. Efeito da redução de gordura e substituição parcial de sal em lingüiça suína tipo toscana. Dissertação apresentada ao programa de pós-graduação em Medicina Veterinária da Universidade Federal Fluminense. 2005.

13. SILVA, D.J. - análise de alimentos (método químicos e biológicos). Viçosa, MG: Universidade Federal de Viçosa, 1990. $165 \mathrm{p}$

14. VAZ, S.K. Elaboração e caracterização de lingüiça fresca "tipo toscana" de tilápia (oreochromis niloticus) dissertação apresentada como requisito parcial à obtenção do grau de mestre, programa de pós-graduação em tecnologia de alimentos, setor de tecnologia da Universidade Federal do Paraná. 2005.

15. Souza, cristina paiva de. Segurança alimentar e doenças veiculadas por alimentos: utilização do grupo coliforme como um dos indicadores de qualidade de alimentos. São paulo. 2006.

16. TERRA. N.N. Defeitos nos Produtos Cárneos: origens e soluções. São paulo: varela 2004

\section{Guilherme S. Miranda \& Cassandra M. T. Ribeiro*}

Federação das Indústrias do Estado do Paraná - Curso Superior de Tecnologia em Alimentos. Rua Júlio de Castilhos 3465. Vila Industrial. CEP 85-904-175, Toledo, Paraná, Brasil.

*E-mail: cassandra.ribeiro@pr.senai.br 